under Irish conditions. All tho common vegetable crops are being grown in a series of field trials. Aspects also being investigated are variety breeding (with emphasis on new varieties suitable for packaging and processing), and weed control.

The glasshouse vegetable work is at present concentrated on tomatoes, cucumbers and lettuces. Already valuable information has been obtained on methods of extending the tomato season. Flower crops under glass are also being examined so that information may be gained which will enable growers to cater for the home and export market.

The Chemistry and Biochemistry Department serves the needs of the vegetable and glasshouse crops sections and a comprehensive research programme is being developed, including work on manurial and trace element problems. It is proposed to build up a large laboratory programme dealing with the chemical and biochemical factors of 'quality' in fruit and vegetables. In addition, work is being done on the chemical aspects of Irish honey-a product capable of great development.

The mushroom research unit is concentrating on the cytological and genetical aspects. A close liaison is maintained with growers and many problems of a practical nature have received attention. To supplement the research facilities at Kinsealy a production unit is available at another centre of An Foras Taluntais. It is proposed to erect a commercial-scale mushroom house at Kinsealy.

A feature of the research work which is of special practical value is that, due to the nearness of the Dublin market, test marketing projects can be carried out on vegetables and flowers in conjunction with the Rural Economy Division of An Foras Taluntais.

The work of the Soil Physics Department deals with research in soil texture and structure, and drainage. The Department also uses Kinsealy as a centre from which soil studies are conducted at a number of other stations. Facilities provided include equipment for soil mechanics and physics, and soil moisture studies. Particular attention is being paid to the water requirements of a number of vegetable crops. In addition, the lysimeter house provides facilities for accurate water balance studies.

The Cereal Chemistry Department has a comprehensive research programme on both the applied and fundamental aspects of wheat and other cereals. Equipment includes drying facilities for 50 samples simultaneously, Brabender grain cleaner, Buhler semi-automatic mill, dough-testers (Brabender farinograph and extensograph) and complete experimental bakery. Factors such as yield, early maturity, resistance to sprouting (of fundamental importance in Ireland because of high rainfall), milling and baking quality, and protein content of wheat are under investigation. Studies on malting and feoding barley are proceeding, and studies on oats are projected.

The Nematology Department undertakes such work as the study of bionomics, host-range and economic importance of eelworms and population studies of eelworms. An important aspect of the work is certification and quarantine of seeds and plants. Other work undertaken includes search for resistant plant varieties, and testing the mode of action and efficiency of nematicides under Irish conditions.

While the research station at Kinsealy is comparatively young, it presents a unique opportunity for co-operation between research workers of many disciplines. As a result of the research programme in hand, much information has already been gained and has been made available to the horticultural and agricultural industry in Ireland.

\title{
NUCLEAR CHEMISTRY
}

A $\mathrm{N}$ informal discussion on nuclear chemistry, organized by the Atomic Energy Research Establishment, Harwell, was held in the Inorganic Chemistry Department at the University of Oxford during September 18-21. The meeting followed similar discussions previously held, at the University of Durham in 1960, and at CERN, Geneva, in 1961. On this occasion the subject was "Fission and other Low Energy Nuclear Processes". Sixty-one papers were presented covering fission, spallation, radioactive decay; the energy released in these processes; and the general techniques for observing them. Abstracts of the papers have been published as a Harwell memorandum number $A E R E-M$ 1078, but in view of the informal nature of the meeting no other record has been made. About 180 delegates attended, representing fifty different laboratories in Europe and the United States.

In the opening paper W. J. Swiatecki (University of California) described recent developments in the liquid drop model of the nucleus, and these were applied by T. Sikkeland (Berkoley) to his work on fission induced by heavy ions. Here the compound nuclei formed by the interaction of heavy ions carbon-12 and oxygen-16 on targets from praseodymium-141 to plutonium-240 cover a wide range of charge to mass ratios. The kinetic energy released was shown to agree closely with detailed predictions of the liquid drop model. In the course of the discussion it was pointed out that the fission energy, which arises from the coulomb repulsion of initially contiguous nuclei, is extremely sensitive to the shape of the nuclei, and provides a valuable means for studying nuclear deformation.

S. G. Thompson (Berkeley), R. H. Tomlinson (MeMaster University, Canada), and R. Vandenbosch (Copenhagen) all reported experimental support to the theoretical picture that at fission one fragment tends to assume a closed shell configuration, whereas the other fragment is more deformable, takes up excitation, and emits neutrons.

Discussion on fission yields concentrated mainly on the relative amounts of isomers of different spin. Radiochemical measurements of the yields of the isomers reported by I. F. Croall (Atomic Energy Research Establishment) implied that the initial fragments were of high angular momentum, and this conformed with the measurements of the directional correlation between prompt $\gamma$-rays and primary fission fragments reported by M. M. Hoffmann (Los Alamos).

Perhaps the most important contributions to the meeting were those on semi-empirical mass formulæ based on the new tables for nuclear masses recently published by Everling, Koenig, Mattauch, and Wapstra. H. Kummel (Max-Planck Institute, Mainz) accounted for the systematic trends in the masses of all known nuclei to an accuracy of $1 \mathrm{MeV}$ by the use of fifty parameters. W. J. Swiatecki showed that 
the major tronds in the deviations of the masses and shapes of nuclei, from those predicted by a liquid drop formula, could be accounted for in a rough way on the basis of a semi-empirical expression with three parameters. These new formulæ should make possible a better assessment of the mass and energy balances in fission which, as diseussed at the meeting, are seriously wrong for uranium-235 and plutonium. 239 fission on the basis of the old mass formulx.

In the session on spallation, K. F. Chackett (Birmingham) interpreted his results from $(p, n)$ reactions on the basis of the optical model of the nucleus, and $\mathbf{N}$. Lefort (Paris) described proton reactions in terms of $\alpha$-particle structures in the nucleus. G. R. Martin (Durham) reported cross. sections for $\left(n,{ }^{3} \mathrm{He}\right)$ reactions, and for $(n, p n)$ processes; the latter seemed to agroo well with a direct interaction model', rather than with an evaporation mechanism. Again, the excitation functions of $(d, 2 n)$ reactions reported by $\mathrm{L}$. J. Gilly (Louvain) failed to agree with predictions of neutron evaporation from compound nuclei. In discussion the general view was expressed that for spallation phenomena the theoretical background is at present very inadequate.

Among the papers on radioactive decay some new isotopes were reported, notably radon-223 (halflife $39.8 \mathrm{~min}$.) and radon-224 (114.8 $\mathrm{min}$ ) by V. J. Robinson (Liverpool). A paper was given by J. Maly (Dubna) on a new method for the preparation of mondelevium by the bombardment of uranium with neon ions, and some details of the chemistry of this element were reported for the first time. Interesting accounts were given of activation processes (M. Lindner, Livermore), and of the production of transuranic elements (J. D. Knight, Los Alamos), in underground nuclear explosions.

The session on chemical effects was restricted to studies in which different nuclear events could be compared. A. G. Maddock (Cambridge) compared the condition of chromium-51 formod by the $(n, \gamma)$ process on chromium-50, with its condition when formed by the $(n, 2 n)$ process on chromium-52 in solid potassium chromate. While no significance could be seen in the initial retention, the subsequent annealing of the material formed in the more highly energetic $(n, 2 n)$ procoss was shown to be slower than the annealing of that from the weaker $(n, \gamma)$ process. In subsequent papers by I. G. Campboll (Manchester), L. Lindner (Amsterdam), and G. E. Miller (Oxford), the importance of the annealing or recombination processes was again emphasized. In the discussion attention was directed to the pressure effects which may influence the 'rigidity' or 'softness' of crystal structures in solids, and 'cage' effects in liquids. F'our papers were given on the effects of fission recoil, and in discussion particular attention was given to the sputtering processes that occur whon fission fragments pass through surfaces.

In sessions on techniques consideration was given mainly to tho problems of flux monitoring. In particular the accurate measurement of roactor neutrons by cobalt activation was described by T. A. Eastwood (Chalk River, Canada) and of neutron spectra from cyclotron targets by A. H. W. Aten, jun. (Amsterdam). New methods for conducting fast chemical separations for measuring short-lived radionuclides were also doscribed. For example, (G. Herrmann (Mainz) showed that thin layers of fresh crystalline precipitates on filters retain a large fraction of their own and rolatod ions from solutions filtered rapidly through them. The most notable advance in recent years in radiochemical techniques for the analysis of mixtures of radioactive isotopes is the use of a mass separator in which the relative amounts of the activity on the different target areas where the different nuclides are deposited is moasured. P'apers by G. Andersson (CERN), and T. A. Eastwood, described this technique, and a third paper was given by H. Ewald (Munich) on the application of a similar technique to the mass separation of highly charged fission fragments during their formation. A refined method for the measurement, by mass spectrometry, of stable fragments (lithium-6 and lithium-7) formed in high-energy proton irradiations was described by E. Gradsztajn (Orsay).

The meoting concluded with deseriptions and comparisons from Livermore and Aldermaston of the computer programmes used in the large-scale analyses of radioactive decay data.
G. N. WaLton

\section{FUTURE OF TEACHING MACHINES}

$\mathrm{P}$ ROF. B. F. SKINNER, of the Department of Psychology, Harvard University, delivered an address on "The Future of Teaching Machines" on Oetober 19 in the University of Oxford, at the invitation of Prof. R. C. Oldfiold. Prof. Skinner began by commenting on the present state of confusion in this field, which is now barely eight years old. This confusion was partly dne to commorcial interost in producing programmed texts, partly to the enormous growth in the needs of education, with ever more students to be taught and ever more to teach them, and partly to the activities of 'gadgeteers' who delighted in inventing a variety of devices which could be referred to as 'teaching machines' but which wero not based on a knowledge of the learning process.

Though education is often considered a preparation for the real world, it is difficult to bring tho real world into the classroom; consequently, education has in practice mainly concerned itself with setting up verbal repertoires of one sort or another, teaching the student to speak a language, to perform mathematics, essentially a vorbal procedure, or to command the facts of a scionce. The first learning machines which had been developed in his department had similarly been directed to the development of verbal skills. They required the student to fill in a missing letter in a word, a word in a sentence, or a term in an equation; if right, the student moves on to a new frame; if wrong, he must try again. In this way he works through the programmo. Present-day programmes advance by very small steps, so that students make few errors and very little repetition is required. Though the material scoms very simple tho studonts move on to advanced technical material very rapidly. The students in his course at Harvard spent their first month using the machines in the "self-instruction room'. At the end of that period he could lecture to them secure in the knowledge that they had mastered the tochnical material necessary for the course.

Two effects of the uso of these machines were worthy of note. The first was the improvement in the pupils' motivation which they produced. In most 